\title{
Poor glycemic control in workers with diabetes mellitus in relation to long working hours: a cross-sectional study
}

\author{
Jongin LEE ${ }^{1}$, Hyoung-Ryoul KIM${ }^{1}$, Tae-Won JANG ${ }^{2}$, Dong-Wook LEE ${ }^{3}$, \\ Chaiho JEONG ${ }^{4}$ and Mo-Yeol KANG ${ }^{1 *}$ \\ ${ }^{1}$ Department of Occupational and Environmental Medicine, Seoul St. Mary's Hospital, \\ College of Medicine, The Catholic University of Korea, Republic of Korea \\ ${ }^{2}$ Department of Occupational and Environmental Medicine, Hanyang University College of Medicine, \\ Republic of Korea \\ ${ }^{3}$ Department of Preventive Medicine, College of Medicine, Seoul National University, Republic of Korea \\ ${ }^{4}$ Division of Endocrinology, Department of Internal Medicine, Seoul St. Mary's Hospital, \\ College of Medicine, The Catholic University of Korea, Republic of Korea
}

Received February 18, 2020 and accepted June 4, 2020

Published online in J-STAGE June 13, 2020

\begin{abstract}
We aimed to investigate the association between working hours and poor glycemic control using a cross-sectional data from the Korea National Health and Nutrition Examination Survey (KNHANES). The participants who were medically diagnosed with diabetes mellitus by a physician were defined as diabetic patients, and patients with hemoglobin A1c (HbA1c) levels $>\mathbf{9 . 0 \%}$ were considered as "poorly controlled". The association of HbA1c level with working hours was examined by linear regression plot, using local regression line and logistic regression analyses. The local regression plot showed a smooth increasing pattern: the longer were the working hours, the higher were the HbA1c levels, even though it was not statistically significant. Odds ratios of working hours over $52 \mathrm{~h}$ per week were higher with the criterion of poor diabetic control (HbA1c $>9.0 \%)$. The results were significant in elderly female workers (odds ratio 3.30, 95\% confidence interval 1.19-9.18). Long working hours were associated with poor glycemic control, specifically among elderly female workers with diabetes.
\end{abstract}

Key words: Working hours, Work environments, Diabetes control, Diabetes management, Elderly workers

\footnotetext{
*To whom correspondence should be addressed.

E-mail: snaptoon@naver.com

(Supplementary material: refer to PMC https://www.ncbi.nlm.nih.gov/ pmc/journals/2597/)

(C)2020 National Institute of Occupational Safety and Health
}

\section{Introduction}

Diabetes mellitus (DM) can lead to various complications, which could be fatal. Patients with DM are treated with lifestyle modifications, oral medications, and insulin injections ${ }^{1}$. The adherence to these treatment modalities can be affected by patient-related and social factors such as age, sex, educational level, and health status ${ }^{2}$. 
DM is a self-managed disease, and patients with DM need to perform various activities such as dietary control, physical exercise, monitoring or adjustment of glucose levels, and utilization of health-care services by themselves. Effective self-management can increase the likelihood of achieving clinically meaningful improvement in glycemic control and thereby reduce complications ${ }^{3)}$. However, daily self-management may be perceived as a burden, because it is a complex, lifelong process requiring considerable patient effort and the need for maintaining the insulin administration schedules ${ }^{4}$. Moreover, because most self-management tasks must be performed several times a day, many patients may become chronically frustrated, discouraged, and/or enraged with the disease that often does not seem to respond to their best efforts ${ }^{5)}$.

The occupational context may be particularly challenging in this respect. Although most adults spend a large proportion of their waking hours working and self-management of diabetes is possible only if smoothly integrated in routine work life, workers with DM often experience difficulties in performing the self-care activities required to manage their condition. Time constraints, need to perform unexpected tasks or attend unexpected events, disruption of usual working routines, physically demanding tasks (complicating glycemic control), and unavailability of appropriate foods are the major occupational factors that impair self-management of diabetes ${ }^{6}$. Further, perceptions of stigma and discrimination, involving the feelings of guilt while spending time on DM management at work, often lead to workers with DM discontinuing treatment requiring workplace accommodations ${ }^{7)}$. Some workers maintain high glucose levels intentionally to prevent impairment of workability or potential hypoglycemia. As a consequence of these working conditions and attitudes, many workers with DM skip glucose level monitoring, physician appointments, and exercises at particular times and report that healthy food consumption was disrupted in the workplace ${ }^{8)}$.

The factors underlying the negative impact of DM, quality of work experiences, and measures to improve them does not receive adequate attention from healthcare professionals and researchers. Thus, knowledge regarding the specific challenges faced in the context of working life and the potential for this context in terms of providing support for self-management of DM represents an unmet need for workers with $\mathrm{DM}^{9}$ ).

Insufficient time for self-management is the key factor that could be related to poor glycemic control among workers with DM. Furthermore, individuals with long work hours might not be able to manage this disease properly because of limited time to monitor blood glucose levels, take insulin or oral medications when necessary, and/ or eat well-balanced meals at regular time intervals. We, therefore, aimed to investigate the relationship between working hours and glycemic control using a nationally representative sample of Korea. Identifying the characteristics associated with this effect (such as differences between gender and age groups) would be helpful for identifying high-risk groups and developing appropriate diabetes management strategies. Therefore, we also examined how the relationship between long working hours and poor glycemic control is modified by gender and age.

\section{Materials and Methods}

\section{Study participants}

We used data from the Korea National Health and $\mathrm{Nu}-$ trition Examination Survey (KNHANES) in this study ${ }^{10}$. KNHANES is a cross-sectional, annual, and national survey that represents the entire population of South Korea. KNHANES surveys three years in a wave-we used the fifth and sixth wave of the KNHANES that were investigated from 2010 to 2015 . The total participants in the two waves were 48,482 ( 8,958 for $2010,8,518$ for $2011,8,058$ for $2012,8,018$ for $2013,7,550$ for 2014 , and 7,380 for 2015)

KNHANES contains self-reports of diagnoses of chronic diseases in each survey participant. The participants were asked if they had been diagnosed with chronic diseases including DM, hypertension, and dyslipidemia. The participants who had been diagnosed with DM by a physician were defined as diabetic patients. Among 48,482 original study participants, 2,539 replied that they had been diagnosed with DM; these participants were enrolled in the study. Participants who did not report working hours per week were excluded. Hence, 1,314 patients were included in this study (Fig. 1).

\section{Patient consent}

All participants gave written informed consent for participation in the study.

\section{Ethics approval}

KNHANES is performed under approval by the Institutional Review Board of Korean Center for Diseases Control and Prevention (KCDC). The approval numbers are 2010-02CON-21-C, 2011-02CON-06-C, 2012-01EXP01-2C, 2013-07CON-03-4C, and 2013-12EXP-03-5C for 


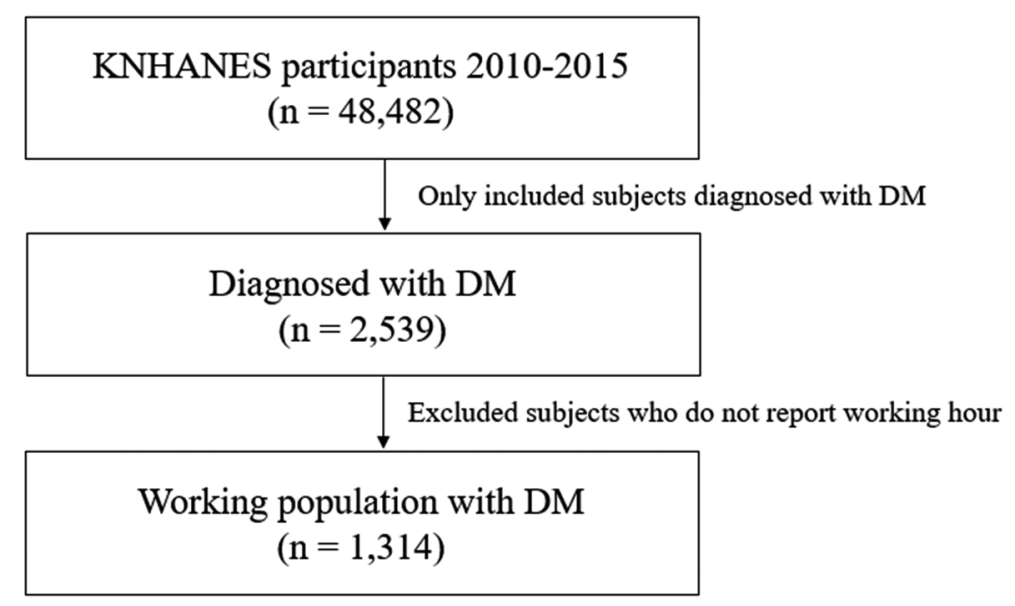

Fig. 1. Selection of study participants. KNHANES: Korean National Health and Nutrition Examination Survey; DM: Diabetes Mellitus.

each survey year from 2010 to 2014. Unlike other survey years of the KNHANES, approval from an institutional review board on the KNHANES VI-3 (survey year 2015) was not necessary according to newly revised Bioethics and Safety Act Article 2 and Enforcement of the Bioethics and Safety Act Article 2-2. The authors analyzed the data from KNHANES VI-3 observing the law.

\section{Glycosylated hemoglobin}

Hemoglobin A1c (HbA1c) level was measured using high performance liquid chromatography with a reagent of HLC-723G8 HbA1c (Tosoh/Japan) by Tosoh G8 (Tosoh/ Japan). Patients with $\mathrm{HbA1c}$ levels $>9.0 \%$ were considered as severely hyperglycemic because if these patients had complications related to DM, insulin injections would be required rather than oral medications ${ }^{11,12)}$; we set this criterion as the definition of "poorly controlled".

\section{Working hours}

KNHANES gathers information on working conditions each year. It contains the following open-ended question: "What are the average hours at work per week including overtime or night work? Mealtime is excluded". Because Korean Labor Standards Act limits maximum working hours per week as $40 \mathrm{~h}$, we defined subjects with working hours of $40 \mathrm{~h}$ or less as a reference group. Regarding overtime work, the Act limits working hours to maximally $52 \mathrm{~h}$ per week. Therefore, we defined two groups representing long working hours: working for $40-52 \mathrm{~h}$ per week and working for more than $52 \mathrm{~h}$ (illegal or some exceptional working conditions).

\section{Demographic variables}

KNHANES provided basic information on sex, age, education level, and individual income. The educational level consists of four levels: below elementary school, middle school, high school, and above college or university. The individual income level has four levels by quartile values of each survey year: low, middle-low, middle-high, and high.

It also provided variables regarding health behavior. Participants were classified into three categories, neversmoker, previous smoker, and current smoker based on their smoking status. The monthly drinking rate was used to assess alcohol intake. Participants who drank more than 1 glass of alcohol were classified into the alcohol drinking group. Participants who performed more than $2.5 \mathrm{~h}$ of moderate physical activity or more than $1.25 \mathrm{~h}$ of both moderate and vigorous physical activity were classified to "yes" group of the variable "physical activity". Body mass indices were calculated using directly measured heights and weights of each subject.

Occupational categories using the major categories of Korean Standard Classification of Occupation were surveyed in KNHANES: 1. Managers, professionals, and related workers, 2. Office workers, 3. Service and sales workers, 4. Agricultural, forestry, and fishery workers, 5. Machine operators and assembling workers, 6. Elementary workers, and 7. Household wives and students.

\section{Statistical analysis}

The demographic characteristics including sex, age, income, educational level, smoking experience, alcohol 
experience, physical activity, body mass index, occupational category, and working hours were compared with the prevalence over poor control of DM using chisquare tests. To visualize the difference in $\mathrm{HbA} 1 \mathrm{c}$ level by working hours, bars and two times the standard errors of $\mathrm{HbA1c}$ levels were plotted.

The association of HbA1c level with working hours was yielded by linear regression adjusted with other variables: sex, age, income, educational level, smoking experience, alcohol experience, physical activity, body mass index, and occupational category. The trend was shown by a plot using local regression line and standard error to visualize the association between two continuous variables-working hours and $\mathrm{HbAlc}$ level ${ }^{13)}$. Linear and local regression analyses were restricted within working hours below $80 \mathrm{~h}$ per week to prevent distortion by unusually large values (outlier); the value that exceeded the legal working hours by two times.

Logistic regression analyses with an independent variable of working hours and dependent variables of the poor control of DM were done. All the analyses were adjusted with other variables suggested in the former chisquare tests including income, educational level, smoking experience, alcohol experience, physical activity, body mass index, and occupational category. Stratified logistic regression analyses were used to explore the association of sex and age. Each odds ratio (OR) was calculated in stratified subgroups: male and female; young ( $<60 \mathrm{yr}$ old) and elderly workers ( $\geq 60 \mathrm{yr}$ old); and elderly male and elderly female workers.

Statistical significance was assessed with a two-sided $p$ value $<0.05$ or $95 \%$ confidence interval in all the tests and analyses. All the statistical methods were analyzed by R program version 3.6.0 (Vienna, Austria) with package "survey" to calculate with the survey-weights of KNHANES.

\section{Results}

A few variables were significantly different between the poorly controlled group (HbAlc $>9.0 \%$ ) and well-controlled group, especially $\mathrm{HbA} 1 \mathrm{c}$ level. Only two variables (age and body mass index) showed statistically significant findings ( $p<0.0001$ and $p=0.0366$, respectively). Young diabetic patients tended to have poor glycemic control. Low body mass index showed a significantly high correlation with poor diabetic control. Occupational and educational categories were not significantly different across the categories. The treatment options were significantly dif- ferent for different $\mathrm{HbAlc}$ levels (Table 1). On comparing $\mathrm{HbA1c}$ levels by working hours, there was no difference between the ages; however, elderly females who were working for $52 \mathrm{~h}$ or more had significantly higher $\mathrm{HbAlc}$ levels than those working for $52 \mathrm{~h}$ or less (Fig. 2).

The linear regression model did not show statistical significance of association $(p=0.120)$ between HbAlc level and working hours. However, the local regression plot showed a smooth increasing pattern: the longer were the working hours, the higher were the HbA1c levels (Fig. 3).

In the logistic regression analyses, ORs of subjects with working hours more than $40 \mathrm{~h}$ per week were higher than the references in all the strata consistently, although statistical significance is not shown (OR $0.82,95 \%$ confidence interval [0.45-1.49] for working 40-52 h, OR 1.47, 95\% CI [0.90-2.41] for working more than $52 \mathrm{~h}$, Table 2). The results were statistically significant in elderly female workers (OR 3.30, 95\% CI [1.19-9.18]).

\section{Discussion}

The primary purpose of this study was to investigate the relationship between working hours and poor glycemic control. The results suggest that long working hours could be associated with poor glycemic control, and the results were especially significant among elderly female workers. These results are consistent with findings from the US and Japanese population. Davila et al. analyzed a representative sample of employed US adults for 20 years with selfreported type 2 diabetes $(n=369)$ and found that adults working for over $40 \mathrm{~h}$ per week were more likely to have suboptimal glycemic control (HbA1c $\geq 7 \%$ ) compared to those working for $20 \mathrm{~h}$ or less (OR 5.09, 95\% CI [1.38$18.76])^{14)}$. A hospital and clinic-based prospective study including 352 male and 126 female working patients with diabetes in Japan showed that working $\geq 60 \mathrm{~h} /$ week (OR $2.92,95 \%$ CI [1.16-7.40]) were predictive of suboptimal glycemic control ${ }^{15)}$. Kivimäki et al. have reported that working for long hours ( $\geq 55 \mathrm{~h}$ per week) is related to the risk of type 2 diabetes, according to a large meta-analysis, only in the case of low socioeconomic status ${ }^{16)}$. Their study suggests that poor glycemic control and the risk of incidence are associated with long working hours.

Long working hours may be related with poor glycemic control owing to several reasons. These may be related to the time constraints (i.e., insufficient time) to properly manage diabetes. For instance, workers may lack time to monitor blood glucose levels or eat regularly as scheduled. In addition, insufficient time is one of the barriers associ- 
Table 1. General characteristics of study participants divided by poor control of diabetes mellitus (HbA1c $>9.0 \%)$

\begin{tabular}{|c|c|c|c|}
\hline & \multicolumn{2}{|c|}{ Poorly controlled $(\mathrm{HbA} 1 \mathrm{c}>9.0 \%)$} & \multirow{2}{*}{$p$-value* } \\
\hline & No & Yes & \\
\hline Sex & & & 0.6246 \\
\hline Male & $734(87.2 \%)$ & $108(12.8 \%)$ & \\
\hline Female & $401(85.0 \%)$ & $71(15.0 \%)$ & \\
\hline Age & & & $<0.0001$ \\
\hline$<60$ & $472(81.1 \%)$ & $110(18.9 \%)$ & \\
\hline$\geq 60$ & $663(90.6 \%)$ & $69(9.4 \%)$ & \\
\hline Income & & & 0.0063 \\
\hline Low & $276(82.4 \%)$ & $59(17.6 \%)$ & \\
\hline Mid-low & $311(88.6 \%)$ & $40(11.4 \%)$ & \\
\hline Mid-high & $251(86.0 \%)$ & $41(14.0 \%)$ & \\
\hline High & $287(88.0 \%)$ & $39(12.0 \%)$ & \\
\hline Educational level & & & 0.3258 \\
\hline Elementary & $432(88.3 \%)$ & $57(11.7 \%)$ & \\
\hline Middle & $195(83.3 \%)$ & $39(16.7 \%)$ & \\
\hline High & $300(84.3 \%)$ & $56(15.7 \%)$ & \\
\hline College & $207(88.5 \%)$ & $27(11.5 \%)$ & \\
\hline Smoking experience & & & 0.3081 \\
\hline Never & $458(84.3 \%)$ & $85(15.7 \%)$ & \\
\hline Previous & $373(89.2 \%)$ & $45(10.8 \%)$ & \\
\hline Current & $295(86.5 \%)$ & $46(13.5 \%)$ & \\
\hline Alcohol experience & & & 0.1447 \\
\hline No & $515(84.0 \%)$ & $98(16.0 \%)$ & \\
\hline Yes & $610(88.7 \%)$ & $78(11.3 \%)$ & \\
\hline Physical activity & & & 0.0621 \\
\hline No & $903(85.3 \%)$ & $155(14.7 \%)$ & \\
\hline Yes & $231(90.6 \%)$ & $24(9.4 \%)$ & \\
\hline Body mass index $\left(\mathrm{kg} / \mathrm{m}^{2}\right)$ & & & 0.0366 \\
\hline$<18.5$ & $13(65.0 \%)$ & $7(35.0 \%)$ & \\
\hline$\geq 18.5$ and $<25.0$ & $586(84.8 \%)$ & $105(15.2 \%)$ & \\
\hline$\geq 25.0$ & $533(88.8 \%)$ & $67(11.2 \%)$ & \\
\hline Occupational category (KSCO) & & & 0.1842 \\
\hline Managers, professionals and related workers & $131(87.3 \%)$ & $19(12.7 \%)$ & \\
\hline Office workers & $73(82.0 \%)$ & $16(18.0 \%)$ & \\
\hline Service and sales workers & $176(83.8 \%)$ & $34(16.2 \%)$ & \\
\hline Agricultural, forestry, and fishery & $206(90.4 \%)$ & $22(9.6 \%)$ & \\
\hline Technicians & $169(86.2 \%)$ & $27(13.8 \%)$ & \\
\hline Manual workers & $234(88.0 \%)$ & $32(12.0 \%)$ & \\
\hline Household, student & $143(83.6 \%)$ & $28(16.4 \%)$ & \\
\hline Working hours & & & 0.1681 \\
\hline$\leq 40$ & $632(88.1 \%)$ & $85(11.9 \%)$ & \\
\hline$>40$ and $\leq 52$ & $217(87.1 \%)$ & $32(12.9 \%)$ & \\
\hline$>52$ & $286(82.2 \%)$ & $62(17.8 \%)$ & \\
\hline Treatment options & & & $<0.0001$ \\
\hline Non-medical only & $11(91.7 \%)$ & $1(8.3 \%)$ & \\
\hline Oral medication with or without non-medical & $936(88.4 \%)$ & $123(11.6 \%)$ & \\
\hline Insulin injection with or without oral/non-medical treatment & $72(72.7 \%)$ & $27(27.3 \%)$ & \\
\hline
\end{tabular}

*p-values from weight-adjusted $\chi^{2}$ tests. 

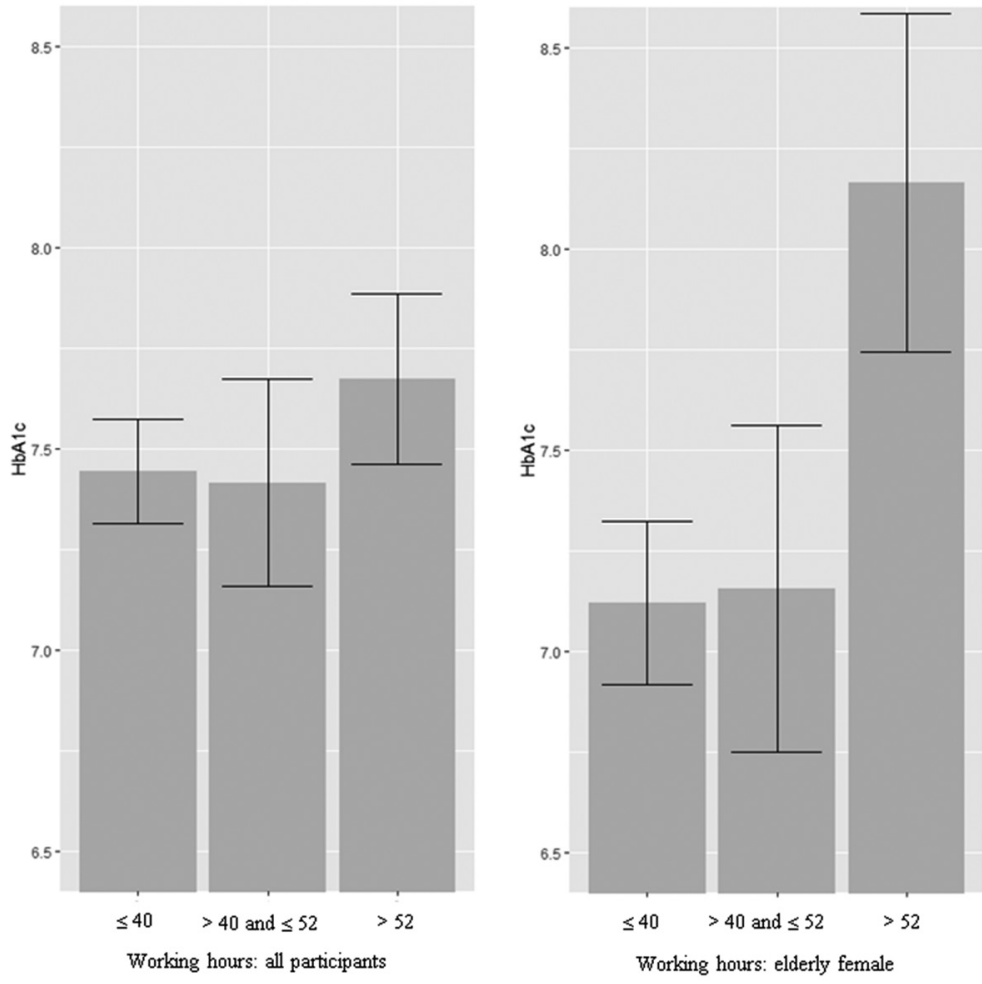

Fig. 2. Distribution of HbA1c levels by working hours in all participants and elderly females.

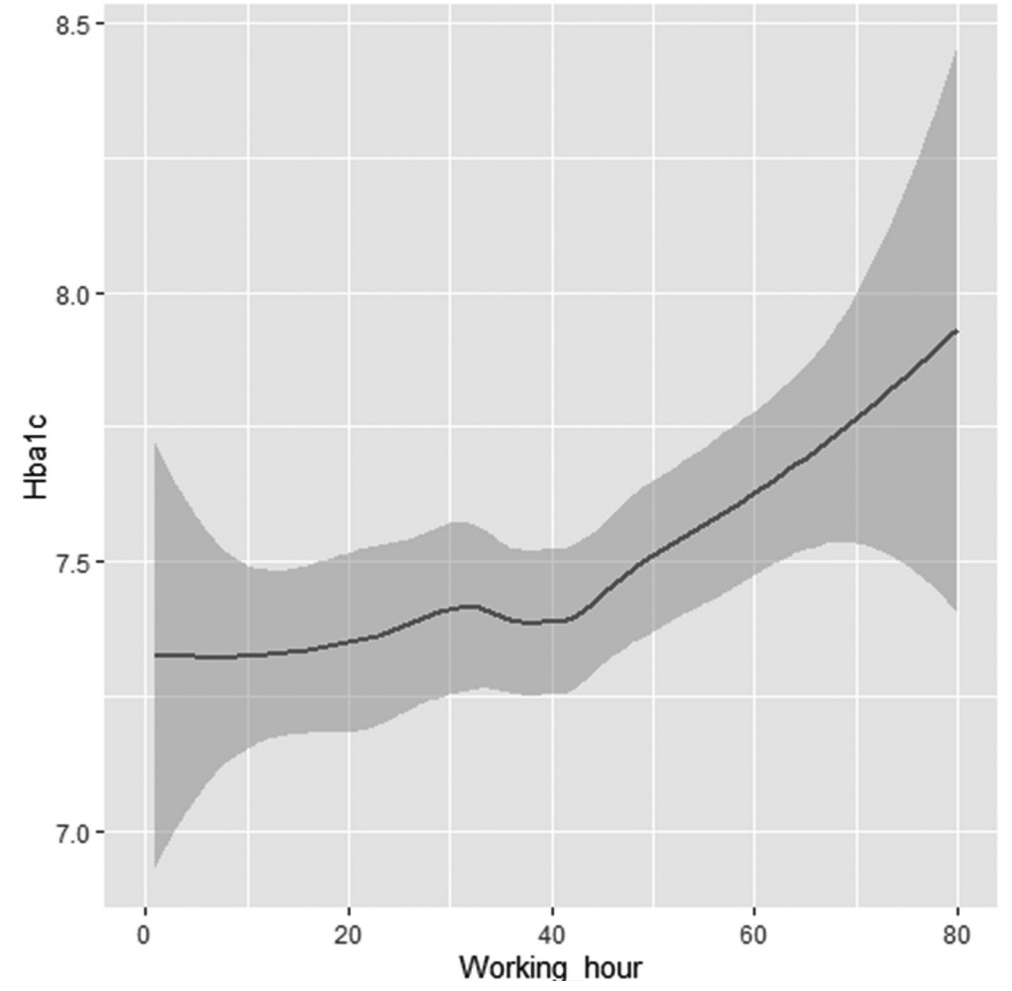

Fig. 3. Local regression plot of an association between working hours and HbA1c. 
Table 2. Stratified and adjusted logistic regression analysis of the association between poor control of diabetes mellitus (HbA1c $>9.0 \%)$ and long working hours

\begin{tabular}{|c|c|c|c|c|c|c|}
\hline Working hours & \multicolumn{2}{|c|}{$\begin{array}{l}\text { Subject with } \\
\mathrm{HbA} 1 \mathrm{c}>9.0 \%\end{array}$} & $\begin{array}{c}\text { Odds ratio } \\
{[95 \% \text { Confidence Interval }]}\end{array}$ & \multicolumn{2}{|c|}{$\begin{array}{l}\text { Subject with } \\
\text { HbAlc }>9.0 \%\end{array}$} & $\begin{array}{c}\text { Odds ratio } \\
{[95 \% \text { Confidence Interval }]}\end{array}$ \\
\hline & \multicolumn{2}{|c|}{ All } & & & & \\
\hline$\leq 40$ & $85 / 717$ & $(11.9 \%)$ & Ref & & & \\
\hline$>40$ and $\leq 52$ & $32 / 249$ & $(12.9 \%)$ & $0.82[0.45-1.49]$ & & & \\
\hline \multirow[t]{2}{*}{$>52$} & $62 / 348$ & $(17.8 \%)$ & $1.47[0.90-2.41]$ & & & \\
\hline & \multicolumn{2}{|c|}{ Male } & & \multicolumn{2}{|c|}{ Female } & \\
\hline$\leq 40$ & $46 / 415$ & $(11.1 \%)$ & Ref & $39 / 302$ & $(12.9 \%)$ & Ref \\
\hline$>40$ and $\leq 52$ & $24 / 177$ & $(13.6 \%)$ & $0.95[0.45-2.01]$ & $8 / 72$ & $(11.1 \%)$ & $0.51[0.19-1.36]$ \\
\hline \multirow[t]{2}{*}{$>52$} & $38 / 250$ & $(15.2 \%)$ & $1.35[0.72-2.56]$ & $24 / 98$ & $(24.5 \%)$ & $1.89[0.91-3.94]$ \\
\hline & \multicolumn{2}{|c|}{ Young (<60 yr old) } & \multicolumn{4}{|c|}{ Elderly ( $\geq 60$ yr old) } \\
\hline$\leq 40$ & $51 / 264$ & $(19.3 \%)$ & Ref & $34 / 453$ & $(7.5 \%)$ & Ref \\
\hline$>40$ and $\leq 52$ & $26 / 142$ & $(18.3 \%)$ & $0.74[0.36-1.52]$ & $6 / 107$ & $(5.6 \%)$ & $0.52[0.16-1.69]$ \\
\hline \multirow[t]{2}{*}{$>52$} & $33 / 176$ & $(18.8 \%)$ & $1.18[0.63-2.23]$ & $29 / 172$ & $(16.9 \%)$ & $1.67[0.81-3.45]$ \\
\hline & \multicolumn{2}{|c|}{ Young male } & \multicolumn{4}{|c|}{ Young female } \\
\hline$\leq 40$ & $26 / 146$ & $(17.8 \%)$ & Ref & $23 / 108$ & $(21.3 \%)$ & Ref \\
\hline$>40$ and $\leq 52$ & $18 / 96$ & $(18.8 \%)$ & $0.80[0.31-2.05]$ & $7 / 39$ & $(17.9 \%)$ & $0.63[0.21-1.91]$ \\
\hline \multirow[t]{2}{*}{$>52$} & $21 / 124$ & $(16.9 \%)$ & $1.21[0.55-2.68]$ & $9 / 45$ & $(20.0 \%)$ & $1.12[0.36-3.48]$ \\
\hline & \multicolumn{2}{|c|}{ Elderly male } & \multicolumn{4}{|c|}{ Elderly female } \\
\hline$\leq 40$ & $19 / 260$ & $(7.3 \%)$ & Ref & $15 / 193$ & $(7.8 \%)$ & Ref \\
\hline$>40$ and $\leq 52$ & $5 / 76$ & $(6.6 \%)$ & $0.68[0.19-2.38]$ & $1 / 31$ & $(3.2 \%)$ & $0.35[0.02-5.63]$ \\
\hline$>52$ & $15 / 121$ & $(12.4 \%)$ & $0.96[0.37-2.49]$ & $14 / 51$ & $(27.5 \%)$ & $3.30[1.19-9.18]$ \\
\hline
\end{tabular}

*All models are adjusted with individual income, educational level, physical activity, body mass index, smoking experience, alcohol experience, and treatment options.

ated with the lack of adherence to a diabetic regimen or treatment. Weijman et al. reported that a high work load was recognized as an obstacle to manage DM properly in both adults with type 1 and type $2 \mathrm{DM}^{17}$ ). Time constraint accompanied with long working hours may also hinder important DM management activities outside of work such as medical check-ups, regular exercises, or consulting a DM healthcare provider or educator.

Moreover, long working hours may lead to poor glycemic control due to a greater tendency of late-night eating. Chronobiological aspects of food intake have been reported to affect insulin levels and to increase glucose intolerance. Cross-sectional studies have suggested that late night meal can cause metabolic syndrome and hyperglycemia in the general Japanese population ${ }^{15)}$. Furthermore, a nocturnal lifestyle is associated with impairment of insulin response to glucose control, resulting in high level of blood glucose concentration between midnight and early morning ${ }^{18)}$.

Long working hours may also result in poor glycemic control due to greater job stress or strain. In many cases, long working hours are likely to coincide with high job demands. The elevated stress levels could result in nega- tive behavioral habits, such as overeating, to compensate such stress. In fact, a strong relationship has been found between work stress and obesity ${ }^{19)}$. Poor glycemic control could also be related to the release of catecholamines and stress hormones (such as cortisol), which have been correlated with increased cardiovascular risks ${ }^{20)}$.

Regarding sex and age differences in association between long working hours and poor glycemic control, the participant's socioeconomic condition should be considered. Elderly female workers who work for long hours might be in an economically challenging situation. Under this circumstance, they cannot afford to manage their health. Moreover, a different level of education could have an impact on poor glycemic control. In our data, female and aged $60 \mathrm{yr}$ old or over participants had a lower education level than males and aged less than 60 (Supplementary Table 1). Because age and the level of education were related to self-management, it can be speculated that elderly women are less educated and probably ignore the importance of self-regulation of diabetes, so they are unable to manage their health properly.

Several limitations were noted in this study: First, the cross-sectional design of our study precludes us from com- 
menting on the causal nature of the relationship between long working hours and poor glycemic control in workers with DM. Because workers with severe DM generally decrease their working hours, the probable result of such an underestimation is a false low-risk scenario. Second, information regarding working hours was based on selfreported questionnaire, which may induce recall bias. However, we expect this bias to work in a non-differential manner. Third, the KNHANES did not distinguish between the types of DM. However, it is clear that proper management is necessary for DM patients regardless of disease type. Because long working hours would act as an obstacle for the proper management of DM, there might be some bias from not distinguishing the type of DM. It is suspected that type $1 \mathrm{DM}$ patients who must use insulin injections might be strongly affected by the association between long working hours and poor glycemic control; this study could not identify it because of the limitation of the original data. Fourth, other possible determinants of glycemic control were not fully controlled, such as compliance to medication and dietary regimen, frequency of selfblood glucose monitoring, and health-related knowledge. Moreover, detailed information about working conditions that may influence glycemic control was not available, such as physical working environment, job titles and work tasks, and information on job stress including number and type of responsibilities, job satisfaction, stressors, social support, job control, and etc. Moreover, some chronic diseases, especially cancers and cardiovascular diseases, might be associated with both working hours and DM control. Therefore, we conducted additional analyses by excluding participants who had cardiovascular disease (angina or myocardial infarction, $\mathrm{n}=80$ ) or cancer (all types, $n=21$ ); there was a slight change in the ORs in the logistic regression (OR 3.53, 95\% CI [1.26-9.85]) for the group of elderly females working for more than $52 \mathrm{~h}$ per week compared with the group of elderly females working for $40 \mathrm{~h}$ or less). Finally, the participants were restricted to workers in South Korea, which limits the generalizability of our findings to other populations, particularly other racial or ethnic groups. To enhance external validity, an additional analysis using a similar survey among different populations should be conducted in the future.

Nevertheless, this study has important strengths. First, this study was performed in a representative sample of the general Korean population. Second, the large sample size with relatively longer working hours (compared to other studies) provided a better opportunity to evaluate the association of working hours on poor glycemic control among workers with diabetes.

In conclusion, long working hours were associated with poor glycemic control specifically among elderly female workers with diabetes. Our results indicated that it would be important to reduce the working hours to succeed in self-management of diabetes. Occupational physicians should be aware of this and apply the same when resolving worker's self-management issues.

\section{Contributors}

The study conception was by MYK and HRK. JL conducted the statistical analysis. DWL, MYK, TWJ, CJ and MYK interpreted the results and revised the reviewed the literature. MYK and JL drafted the manuscript. MYK and JL revised the manuscript. All authors have read and approved the final version of the submitted manuscript.

\section{Funding}

This research received no specific grant from any funding agency, commercial or not-for-profit sectors.

\section{Conflict of Interest}

None declared.

\section{Data Sharing Statement}

Details of the Korea National Health and Nutrition Examination Survey are available on the survey's website (https://knhanes.cdc.go.kr/knhanes/eng/index.do).

\section{Acknowledgment}

We thank the Korea Center for Disease Control and Prevention for providing KNHANES data.

\section{References}

1) Ko SH, Hur KY, Rhee SY, Kim NH, Moon MK, Park SO, Lee BW, Kim HJ, Choi KM, Kim JH, Committee of Clinical Practice Guideline of Korean Diabetes Association (2017) Antihyperglycemic agent therapy for adult patients with type 2 diabetes mellitus 2017: a position statement of the Korean Diabetes Association. Korean J Intern Med (Korean Assoc Intern Med) 32, 947-58. [Medline]

2) Krass I, Schieback P, Dhippayom T (2015) Adherence to diabetes medication: a systematic review. Diabet Med 32, 725-37. [Medline] [CrossRef] 
3) Chrvala CA, Sherr D, Lipman RD (2016) Diabetes selfmanagement education for adults with type 2 diabetes mellitus: a systematic review of the effect on glycemic control. Patient Educ Couns 99, 926-43. [Medline] [CrossRef]

4) Vermeire E, Wens J, Van Royen P, Biot Y, Hearnshaw $\mathrm{H}$, Lindenmeyer A (2005) Interventions for improving adherence to treatment recommendations in people with type 2 diabetes mellitus. Cochrane Database Syst Rev CD003638. [Medline]

5) Polonsky WH (2000) Understanding and assessing diabetes-specific quality of life. Diabetes Spectr 13, 36.

6) Loerbroks A, Nguyen XQ, Vu-Eickmann P, Krichbaum M, Kulzer B, Icks A, Angerer P (2018) Psychosocial working conditions and diabetes self-management at work: a qualitative study. Diabetes Res Clin Pract 140, 129-38. [Medline] [CrossRef]

7) Bose J (2013) Promoting successful diabetes management in the workplace. Int J Work Heal Manage 6, 205-26 [CrossRef].

8) Balfe M, Brugha R, Smith D, Sreenan S, Doyle F, Conroy R (2014) Why do young adults with Type 1 diabetes find it difficult to manage diabetes in the workplace? Health Place 26, 180-7. [Medline] [CrossRef]

9) Cleal B, Willaing I, Stuckey H, Peyrot M (2019) Work matters: diabetes and worklife in the second diabetes attitudes, wishes and needs (DAWN2) study. Diabetes Res Clin Pract 150, 90-8. [Medline] [CrossRef]

10) Kweon S, Kim Y, Jang MJ, Kim Y, Kim K, Choi S, Chun C, Khang YH, Oh K (2014) Data resource profile: the Korea national health and nutrition examination survey (KNHANES). Int J Epidemiol 43, 69-77. [Medline] [CrossRef]

11) Nathan DM, Genuth S, Lachin J, Cleary P, Crofford O, Davis M, Rand L, Siebert C, Diabetes Control and Complications Trial Research Group (1993) The effect of intensive treatment of diabetes on the development and progression of long-term complications in insulindependent diabetes mellitus. N Engl J Med 329, 977-86. [Medline] [CrossRef]

12) Garber AJ, Abrahamson MJ, Barzilay JI, Blonde L, Bloomgarden ZT, Bush MA, Dagogo-Jack S, DeFronzo RA, Einhorn D, Fonseca VA, Garber JR, Garvey WT, Grunberger G, Handelsman Y, Hirsch IB, Jellinger PS, McGill JB, Mechanick JI, Rosenblit PD, Umpierrez GE (2019) Consensus statement by the American association of clinical endocrinologists and American college of endocrinology on the comprehensive type 2 diabetes management algorithm - 2019 executive summary. Endocr Pract 25, 69-100. [Medline] [CrossRef]

13) Cleveland WS, Grosse E (1991) Computational methods for local regression. Stat Comput 1, 47-62 [CrossRef].

14) Davila EP, Florez H, Trepka MJ, Fleming LE, Niyonsenga T, Lee DJ, Parkash J (2011) Long work hours is associated with suboptimal glycemic control among US workers with diabetes. Am J Ind Med 54, 375-83. [Medline] [CrossRef]

15) Azami Y, Funakoshi M, Matsumoto H, Ikota A, Ito K, Okimoto H, Shimizu N, Tsujimura F, Fukuda H, Miyagi C, Osawa S, Osawa R, Miura J (2019) Long working hours and skipping breakfast concomitant with late evening meals are associated with suboptimal glycemic control among young male Japanese patients with type 2 diabetes. J Diabetes Investig 10, 73-83. [Medline] [CrossRef]

16) Kivimäki M, Virtanen M, Kawachi I, Nyberg ST, Alfredsson L, Batty GD, Bjorner JB, Borritz M, Brunner EJ, Burr H, Dragano N, Ferrie JE, Fransson EI, Hamer M, Heikkilä K, Knutsson A, Koskenvuo M, Madsen IEH, Nielsen ML, Nordin M, Oksanen T, Pejtersen JH, Pentti J, Rugulies R, Salo P, Siegrist J, Steptoe A, Suominen S, Theorell T, Vahtera J, Westerholm PJM, Westerlund H, Singh-Manoux A, Jokela M (2015) Long working hours, socioeconomic status, and the risk of incident type 2 diabetes: a meta-analysis of published and unpublished data from 222120 individuals. Lancet Diabetes Endocrinol 3, 27-34. [Medline] [CrossRef]

17) Weijman I, Ros WJG, Rutten GEHM, Schaufeli WB, Schabracq MJ, Winnubst JAM (2005) The role of workrelated and personal factors in diabetes self-management. Patient Educ Couns 59, 87-96. [Medline] [CrossRef]

18) Qin LQ, Li J, Wang Y, Wang J, Xu JY, Kaneko T (2003) The effects of nocturnal life on endocrine circadian patterns in healthy adults. Life Sci 73, 2467-75. [Medline] [CrossRef]

19) Siegrist J, Rödel A (2006) Work stress and health risk behavior. Scand J Work Environ Health 32, 473-81. [Medline] [CrossRef]

20) Heinz A, Hermann D, Smolka MN, Rieks M, Gräf KJ, Pöhlau D, Kuhn W, Bauer M (2003) Effects of acute psychological stress on adhesion molecules, interleukins and sex hormones: implications for coronary heart disease. Psychopharmacology (Berl) 165, 111-7. [Medline] [CrossRef] 